\title{
Mycoplasma fermentans, but not $M$ penetrans, detected by PCR assays in synovium from patients with rheumatoid arthritis and other rheumatic disorders
}

\author{
T Schaeverbeke, C B Gilroy, C Bébéar, J Dehais, D Taylor-Robinson
}

MRC Sexually

Transmitted Diseases Research Group, Imperial College School of Medicine at St Mary's, Paddington, London

C B Gilroy

D Taylor-Robinson

Service de

Bactériologie, Hôpital Pellegrin, Centre Hospitalier Universitaire de

Bordeaux, Bordeaux,

France

C Bébéar

\section{Service de}

Rhumatologie, Hôpital Pellegrin T Schaeverbeke

J Dehais

Correspondence to: Prof D Taylor-Robinson, MRC Sexually Transmitted Diseases Research Group, Jefferiss Trust Laboratories, Imperial College School of Medicine at St Mary's, Paddington,

London W2 $1 \mathrm{NY}$.

Accepted for publication 16 July 1996

\begin{abstract}
Aim/background-Mycoplasmas, especially Mycoplasma fermentans, were suggested more than 20 years ago as a possible cause of rheumatoid arthritis but this hypothesis was never substantiated. In view of the superior sensitivity of the polymerase chain reaction (PCR) assay over culture, the aim was to use this method to seek $M$ fermentans and $M$ penetrans in synovial samples from patients with various arthritides.
\end{abstract}

Methods-Synovial fluid samples ( $n=$ 154) and synovial biopsy specimens ( $n=$ 20) from 133 patients with various rheumatic disorders were stored at $-80^{\circ} \mathrm{C}$ for between one and $\mathbf{4 0}$ months. Aliquots (500 $\mu \mathrm{l})$ of the synovial fluid samples were centrifuged and the deposit, and also the synovial biopsy specimens (approximately $1 \mathrm{~g})$ were placed in lysis buffer with proteinase $K$ for DNA extraction. The DNA was tested by using a semi-nested PCR assay for $M$ fermentans and a single-round PCR for $M$ penetrans.

Results-M fermentans was detected in the joints of eight (21\%) of 38 patients with rheumatoid arthritis, two $(20 \%)$ of 10 patients with spondyloarthropathy with peripheral arthritis, one $(20 \%)$ of five patients with psoriatic arthritis, and four (13\%) of 31 patients with unclassified arthritis. $M$ fermentans was not found in the joints of the seven patients with reactive arthritis, the 29 with osteoarthritis or post-traumatic hydrarthrosis, the nine with gouty arthritis, nor the four with chronic juvenile arthritis. $M$ penetrans was not detected in any sample.

Conclusions-These findings show that the presence of $M$ fermentans in the joint is associated with inflammatory rheumatic disorders of unknown cause, including rheumatoid arthritis. However, whether this organism triggers or perpetuates disease or behaves as a passenger remains conjectural.

(F Clin Pathol 1996;49:824-828)

Keywords: Mycoplasma fermentans, Mycoplasma penetrans, rheumatoid arthritis, rheumatic disorders, PCR.

Rheumatoid arthritis is a chronic destructive polyarthritis of unknown cause. There are sev- eral manifestations of autoimmunity in rheu- $\vec{\circ}$ matoid arthritis and the possible role of viruses or slow growing bacteria in triggering the disease has been discussed..$^{1-3}$ Mycoplasmas are a cause of acute and chronic arthritis in many animal species ${ }^{4}$ and, therefore, should at least be considered as candidates for causing human $\circ$ disease. Mycoplasma fermentans was suggested more than 20 years ago as a cause of rheumatoid arthritis on the basis of isolation from the synovial fluid of a few patients with this condition. ${ }^{5}$ Furthermore, Williams et al $l^{6}$ showed that migration of leucocytes from two thirds of patients with rheumatoid arthritis was inhibited by membrane fragments of $M$ fermentans. However, although other authors ${ }^{7}$ have iso- ? lated $M$ fermentans from a small proportion of patients with rheumatoid arthritis, there have been many attempts which have failed. ${ }^{9}$ In addition, $M$ fermentans seemed an unlikely candidate because it was considered at the time to be only a rare isolate from the genitourinary $\overline{\vec{z}}$ tract. ${ }^{10}$ More recently, by use of polymerase $\exists$ chain reaction (PCR) technology, this mycoplasma has been found in the throats of more than $20 \%$, the peripheral blood leucocytes of about $10 \%$ and the urine of about $5 \%$ of both HIV positive and HIV negative patients. ${ }^{11}$ In view of this it seemed worthwhile reevaluating $\delta$ the possible presence of $M$ fermentans in the joints of patients with rheumatoid arthritis 윽 using the PCR technique. For comparison, and $D$ because this mycoplasma has also been isolated from a few patients with other rheumatic N disorders, ${ }^{78}$ we examined synovial samples from patients with other arthritic conditions. As other mycoplasmas may be involved, it $\omega$ seemed of value to also seek $M$ penetrans, the most recent of the mycoplasmas of human origin to be recognised. It was isolated from urine samples of patients with AIDS, ${ }^{12}$ but its prefered site of localisation and significance are unknown.

\section{Methods}

SAMPLES AND PATIENTS

From May 1992 to August 1995, 154 synovial fluid and 20 synovial biopsy specimens were collected in the Rheumatology Department of ? the Centre Hospitalier Universitaire de Bordeaux. These specimens were from patients in nine clinical categories, as follows: 38 synovial fluid samples from 28 patients and 10 synovial biopsy specimens from 10 patients with 
Table 1 Frequency of $\mathrm{M}$ fermentans detection in the different disease groups and comparability of the groups in respect of age and sample storage duration

\begin{tabular}{|c|c|c|c|c|c|c|c|c|c|}
\hline & & \multicolumn{8}{|l|}{ Disease } \\
\hline & & $R A$ & $\operatorname{Re} A$ & $S P A$ & Pso $A$ & $U L A$ & $C f A$ & $O A+H A$ & $G A$ \\
\hline \multirow{4}{*}{$\begin{array}{l}\text { Number of patients } \\
\text { Sex ratio } \\
\text { Age }\end{array}$} & & 38 & 7 & 10 & 5 & 31 & 4 & 29 & 9 \\
\hline & $\mathrm{M} / \mathrm{F}$ & $11 / 27$ & $5 / 2$ & $6 / 4$ & $4 / 1$ & $19 / 12$ & $3 / 1$ & $11 / 18$ & $9 / 1$ \\
\hline & mean $(\mathrm{SD})$ & $62(15)$ & 49 (12) & $39(19)$ & $48(17)$ & $52(17)$ & $13(2)$ & $62(11)$ & $64(12)$ \\
\hline & range & $23-75$ & $36-74$ & $18-77$ & $29-72$ & $23-81$ & $11-15$ & $27-73$ & $48-79$ \\
\hline \multirow{2}{*}{$\begin{array}{l}\text { Storage duration } \\
\text { (months) } \\
M \text { fermentans }\end{array}$} & mean $(\mathrm{SD})$ & $19(13)$ & $10(12)$ & $18(15)$ & $24(16)$ & $21(13)$ & $11(11)$ & $17(14)$ & $25(11)$ \\
\hline & range & $1-39$ & $2-40$ & $1-40$ & $3-40$ & $1-39$ & $5-32$ & $1-40$ & $2-40$ \\
\hline
\end{tabular}

$\mathrm{RA}=$ rheumatoid arthritis; $\mathrm{ReA}=$ reactive arthritis; $\mathrm{SPA}=$ spondyloarthropathy with peripheral arthritis; Pso $\mathrm{A}=$ psoriatic arthritis; UIA $=$ unclassified inflammatory arthritis; $\mathrm{CJA}=$ chronic juvenile arthritis; $\mathrm{OA}=$ osteoarthritis; $\mathrm{HA}=$ post-traumatic hydrathrosis; $\mathrm{GA}=$ gouty arthritis.

rheumatoid arthritis, classified according to the American College of Rheumatology (ARA) criteria ${ }^{13} ; 11$ synovial fluid samples from seven patients with reactive arthritis, defined as an arthritis following a genital non-gonococcal infection or an enteric infection; 25 synovial fluid samples from 10 patients with spondyloarthropathy with peripheral arthritis, classified according to the European Spondyloarthropathy Study Group (ESSG) criteria $^{14}$; five synovial fluid samples from five patients with psoriatic arthritis; 39 synovial fluid samples from 31 patients with unclassified arthritis; six synovial fluid samples from four patients with chronic juvenile arthritis (two of whom were B27 positive); 17 synovial fluid samples from 16 patients and 10 synovial biopsy specimens from 10 patients with osteoarthritis; three synovial fluid samples from three patients with post-traumatic hydrarthrosis; and 10 synovial fluid samples from nine patients with gouty arthritis. These patients' data are summarised in table 1. All of the samples were stored at $-80^{\circ} \mathrm{C}$ for between one and 40 months.

PROCESSING OF SAMPLES

After thawing, a $500 \mu$ laliquot of each of the synovial fluid samples was diluted with an equal volume of phosphate buffered saline (PBS) and centrifugated at $13000 \times g$ for 15 minutes. The DNA was then extracted from the pellet according to a standard protocol ${ }^{15}$ with the following modifications. The synovial fluid sample pellet was resuspended in lysis buffer (10 mM Tris- $\mathrm{mCl}, \mathrm{pH} 7.6,1 \mathrm{mM}$ EDTA, 1\% sodium dodecyl sulphate, and 100 $\mu \mathrm{g} / \mathrm{ml}$ proteinase $\mathrm{K}$ (Sigma, Poole, Dorset, UK)). A negative control (lysis buffer only) was included with each group of five specimens and all tubes were incubated at $37^{\circ} \mathrm{C}$ for two hours instead of one. The synovial biopsy specimens (approximately $1 \mathrm{~g}$ ) were placed directly in the lysis buffer, with a double concentration of proteinase $\mathrm{K}$ and incubated at $37^{\circ} \mathrm{C}$ overnight. The remainder of the extraction was according to the standard protocol ${ }^{15}$ and the final DNA pellet was resuspended in $100 \mu \mathrm{l}$ distilled water.

\section{PCR ASSAYS}

An aliquot $(5 \mu \mathrm{l})$ of each DNA preparation was used in the PCR assay for $M$ fermentans. The semi-nested procedure described previously ${ }^{11}$ was used with the following modifications. The thermal cycling profile for each round of amplification comprised 35 cycles at $95^{\circ} \mathrm{C}$ for
30 seconds ( 60 seconds in the first cycle), $55^{\circ} \mathrm{C}$ for 30 seconds and $72^{\circ} \mathrm{C}$ for 60 seconds (increased to 10 minutes for the final cycle). The product from the first round $(1 \mu \mathrm{l})$ was added to $49 \mu$ fresh PCR mixture for the second round of amplification, using the same cycle profile as above. An aliquot $(10 \mu \mathrm{l})$ of the second round product was analysed on a $2 \%$ agarose gel. Positive samples, indicated by a 104 base pair product, were confirmed by Southern blot analysis using an internal oligonucleotide RW005 (GGTTATTCGATTTCTAAATCGCCT) labelled with digoxigenin (Boehringer) as a probe. Gels of all of the samples from patients with osteoarthritis, posttraumatic and gouty arthritis that were negative were also blotted for confirmation of negativity.

For $M$ penetrans, the set of primers described by Grau et al was used. ${ }^{16}$ An aliquot $(10 \mu \mathrm{l})$ of each DNA preparation was added to $40 \mu \mathrm{l}$ of the reaction mixture $(10 \mathrm{mmol} / 1$ Tris- $\mathrm{HCl}, \mathrm{pH}$ $8.3,50 \mathrm{mmol} / 1$ potassium chloride, $2 \mathrm{mmol} / 1$ magnesium chloride, $0.1 \%$ gelatin, $200 \mu \mathrm{mol} / 1$ of each deoxynucleotide triphosphate, 0.2 $\mu \mathrm{mol} / \mathrm{l}$ of each primer, and 1.25 units Taq polymerase). The thermal cycling profile of amplification comprised 35 cycles at $95^{\circ} \mathrm{C}$ for 60 seconds ( 120 seconds in the first cycle), $55^{\circ} \mathrm{C}$ for 60 seconds, and $72^{\circ} \mathrm{C}$ for 60 seconds (increased to 10 minutes for the final cycle). An aliquot of $10 \mu \mathrm{l}$ of the second round product was analysed on a $2 \%$ agarose gel.

STATISTICAL ANALYSIS

Fischer's exact test was used to compare proportion and unpaired Student's $t$ test for mean comparisons.

\section{Results}

MYCOPLASMA DETECTION AND DISEASE ASSOCIATION

$M$ penetrans was not detected in any sample, even though the assay was sensitive down to $10^{-15} \mathrm{~g}$ DNA. Conversely, $M$ fermentans was detected in 15 specimens, each from a different patient, all of whom had an inflammatory rheumatic disorder (table 1). Thus, synovial fluid samples from four (14\%) of 28 patients with rheumatoid arthritis were positive, as were synovial biopsy specimens from four $(40 \%)$ of 10 patients with rheumatoid arthritis, so that, overall, the mycoplasma was detected in the joints of eight $(21 \%)$ of 38 patients with rheumatoid arthritis. In addition, $M$ fermentans was detected in synovial fluid samples from two 
Table 2 Comparison of $\mathrm{M}$ fermentans positive and negative patients

\begin{tabular}{|c|c|c|c|c|c|c|c|}
\hline & & \multicolumn{6}{|l|}{ Disease } \\
\hline & & $R A$ & & $S P A$ & & $U I A$ & \\
\hline \multicolumn{2}{|l|}{$M$ fermentans } & + & - & + & - & + & - \\
\hline \multirow{2}{*}{ Age } & mean $(S D)$ & $61(12)$ & $62(16)$ & $57(14)$ & 35 (19) & $61(8)$ & $52(18)$ \\
\hline & range & $36-74$ & $23-75$ & $47-67$ & $18-77$ & $49-67$ & $23-81$ \\
\hline Sex ratio & $\mathrm{M} / \mathrm{F}$ & $2 / 6$ & $9 / 21$ & $2 / 0$ & $4 / 4$ & $3 / 1$ & $16 / 11$ \\
\hline \multirow{2}{*}{ Disease duration (years) } & mean $(\mathrm{SD})$ & $6(3)$ & $7(6)$ & $19(22)$ & $7(9)$ & $6(4)$ & $3(3)$ \\
\hline & range & $1-10$ & $1-25$ & $3-34$ & $0.3-22$ & $1-10$ & $0.2-14$ \\
\hline (mm/hour) & range & $57-78$ & $12-137$ & $13-124$ & $12-96$ & $18-55$ & $12-107$ \\
\hline Synovial cells & mean $(\mathrm{SD})$ & $23(18)$ & $18(12)$ & $5(5)$ & $14(17)$ & $21(13)$ & $23(22)$ \\
\hline$\left(\times 1000 / \mathrm{mm}^{3}\right)$ & range & $12-50$ & $4.8-55$ & $1.6-8.5$ & $1.6-90$ & $7.4-35$ & $2-93$ \\
\hline $\mathrm{RF}+$ & $\mathrm{n}$ & $4 / 6$ & $19 / 29$ & $0 / 1$ & $0 / 6$ & $0 / 4$ & $3 / 26$ \\
\hline ANA+ & n & $2 / 7$ & $11 / 26$ & $0 / 1$ & $1 / 6$ & $2 / 4$ & $7 / 26$ \\
\hline B27+ & $\mathrm{n}$ & $0 / 2$ & $2 / 17$ & $0 / 2$ & $5 / 8$ & $1 / 4$ & $1 / 26$ \\
\hline
\end{tabular}

$\mathrm{ESR}=$ erythrocyte sedimentation rate; $\mathrm{RF}=$ rheumatoid factor; $\mathrm{ANA}=$ antinuclear antibodies.

(20\%) of 10 patients with spondyloarthropathy with peripheral arthritis, one $(20 \%)$ of five patients with psoriatic arthritis and four $(13 \%)$ of 31 patients with unclassified arthritis. In contrast, none of the synovial fluid samples of the four patients with chronic juvenile arthritis and the seven patients with reactive arthritis, and none of the 40 specimens from the 38 patients with non-inflammatory arthropathies and crystal associated synovitis-that is posttraumatic effusion, osteoarthritis and gouty arthritis, was positive. Thus, $M$ fermentans was detected significantly more often in the joints of patients with inflammatory rheumatic diseases than in those of patients with noninflammatory arthropathies (15/95 $v 0 / 38, \mathrm{p}<$ 0.01 , odds ratio $=12$ ). This was also the case when patients with rheumatoid arthritis were compared with patients with non-inflammatory arthropathies $(8 / 38 v 0 / 38, \mathrm{p}<0.01$, odds ratio $=17$ ).

FEATURES OF M FERMENTANS POSITIVE PATIENTS The patients with rheumatoid arthritis, two men and six women, had classic disease that was rheumatoid factor positive in four of the six in whom the test was undertaken. The two patients with spondyloarthropathy were both B27 negative men; one had a history of ankylosing spondylitis which had been in complete remission for a considerable time when, at the age of 67 years, he developed arthritis of both knees associated with ankle and heel pain. The other man, who was 47 years old, had a three year history of successive bouts of arthritis of one or both knees associated with chest and dorso-lumbar pain and pseudo-sciatica which responded to non-steroidal antiinflammatory drugs. At the time synovial fluid was collected for this study, his cell count was $1600 / \mathrm{mm}^{3}$, but had been up to $5000 / \mathrm{mm}^{3}$ several times before. The patient with psoriatic arthritis had a long history of psoriatic dermatitis associated with attacks of synovitis involving sometimes one knee, one elbow or both shoulders. Although his arthritis has been classified as psoriatic, it could also be classified as peripheral spondyloarthropathy as it fulfills the ESSG criteria. The patients with unclassified inflammatory arthritis comprised a B27 positive woman with a five year history of symmetrical non-erosive polyarthritis associated with psoriasis, who also had a high titre of antinuclear antibodies $(1: 1000)$; a 62 year old $\overrightarrow{\vec{\omega}}$ B27 negative man who had a 10 year history of $\stackrel{\sigma}{.}$ chronic non-erosive oligoarthritis with low lev- 융 els of rheumatoid factor and no antinuclear $\vec{c}$ antibodies; a 49 year old man who had a recent and recurrent monoarthritis of the knee, without any other feature; a 67 year old man who $\stackrel{\sim}{\sim}$ had, in the $1970 \mathrm{~s}$, acute episodes of monoar- 을 thritis of knees and ankles regarded as gout when he presented in 1986 with polyarthritis. In 1993, this patient developed a chronic sym- 웅 metrical polyarthritis. The synovial fluid, collected several times, never contained crystals and a synovial biopsy specimen showed a non- $\varnothing$ specific synovitis with a lymphocytic infiltrate and no crystal deposits. Therefore, the diagnosis of polyarticular gout could be excluded. Moreover, his symmetrical polyarthritis was associated with a significant titre of antinuclear antibodies $(1: 250)$ and a low level of anti-DNA antibody (7.4 IU). He had no rheumatoid factor and was B27 negative.

As shown in table 2 , sex ratios, erythrocyte sedimentation rate values, synovial cell counts, rheumatoid factor, antinuclear antibodies, and

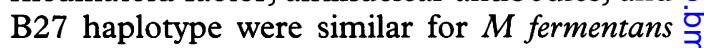
positive and negative patients in each group.

\section{Discussion}

In view of the specificity and sensitivity of the $\mathrm{PCR}^{11}$ and the numerous negative controls we used in this study, we conclude that a positive result on agarose gel, confirmed by Southern blotting, is indicative of $M$ fermentans in the $N$ joint. It was located in this site in about $20 \%$ of $\omega$ patients with inflammatory rheumatic diseases, including rheumatoid arthritis, although $M$ fer-

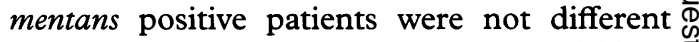
from $M$ fermentans negative patients within a clinical category. The mycoplasma was never $\frac{0}{0}$ detected in any sample from patients with $\overrightarrow{\mathbb{D}}$ reactive arthritis, chronic juvenile arthritis, $\frac{\rho}{\mathbb{D}}$ osteoarthritis, post-traumatic hydrarthrosis, or $\varrho$ gouty arthritis. Furthermore, we could not detect $M$ penetrans in any sample, whatever the disease, although it could be argued that the sensitivity of the two PCR assays used in our study is not exactly the same. A semi-nested PCR was used for $M$ fermentans and a singleround PCR for $M$ penetrans, and the set of primers for $M$ fermentans was chosen in a repetitive DNA sequence. It has been shown that different strains of $M$ fermentans (incogni- 
tus strains) contain more than 10 copies of this sequence. ${ }^{17}$ Such a repetitive target may increase the sensitivity of a PCR assay.

What could be the significance of the association between $M$ fermentans and inflammatory rheumatic diseases? By means of the PCR assay, $M$ fermentans has been found quite frequently in the throat and also associated with peripheral blood mononuclear cells of $9-10 \%$ of both HIV positive homosexual patients and HIV negative individuals attending a sexually transmitted diseases clinic. ${ }^{11}$ If this finding extends to the general population, it is clear that the opportunity for spread of the mycoplasma to joints is enhanced for a large number of people, especially in the case of inflammatory arthritides because of the migration to the joint of inflammatory cells from the blood. However, if inflammatory cells carry $M$ fermentans, the expectation would be to find the organism in the joints of patients with gouty arthritis, which is also characterised by a neutrophil accumulation in the joint during the acute phase. The organism was not found in such patients so that its presence in the joints of other patients with an inflammatory arthritis may not be entirely secondary and a consequence of the disease. However, the immune dysfunction which characterises the rheumatic diseases and the corticosteroids often prescribed could further promote dissemination to the joints of organisms in the blood or those normally part of the resident mucosal flora. This is possible, but opportunistic infections are not a common feature of either rheumatoid arthritis or spondyloarthropathies. Moreover, the disease in two patients was at an early stage when the synovial fluid was collected and they were unlikely to have been immunosuppressed, at least by the treatment.

The second possible explanation for the findings is that $M$ fermentans in the joint behaves as a primary trigger for the inflammatory rheumatic diseases or perpetuates them, or both. In this regard, it is interesting that the arthritogenicity of this mycoplasma has been demonstrated experimentally in rabbits. ${ }^{18}$ If it does behave as a trigger, why was it not detected more often in this study? Although the PCR assay is more sensitive than culture, it is possible that its sensitivity in tests on clinical samples is reduced, as shown for $M$ pneumoniae in respiratory secretions. ${ }^{19}$ Moreover, it has been shown in experimentally induced mycoplasmal arthritis that organisms could be detected only in the early and not the late stage of disease, ${ }^{20}$ and the majority of specimens were taken from patients during the chronic phase. Alternatively, a triggering organism could reside mainly in another site and disseminate occasionally to the joint. Finally, different micro-organisms, and, indeed, mycoplasmas other than $M$ fermentans, could have arthritogenic properties and be involved in the same disease, reminiscent of the polymicrobial triggering of reactive arthritis. In this regard, it is interesting to note that Chlamydia trachoma$t i s$, which is known to be involved in reactive arthritis, ${ }^{21}$ has recently been reported to exist in synovial specimens from $24 \%$ of patients with early rheumatoid arthritis. ${ }^{22}$ It is also noteworthy that $M$ genitalium has been detected by PCR technology in the joints of two of 13 patients with arthritis, one with sexually acquired reactive arthritis and the other with seronegative rheumatoid arthritis. ${ }^{23}$ The role of this and other mycoplasmas in comparison with $M$ fermentans needs to be explored.

The fact that $M$ fermentans was not related to a single disease, but found in rheumatoid arthritis, spondyloarthropathies and unclassified arthritis could mean that it acts as a trigger for all of them and that differences in the genetic background associated with each disease, and the related pathway of the immune response, explain the different clinical features. Moreover, this could explain the heterogeneity of some of these diseases, such as unclassified arthritis or psoriatic arthritis, and the frequency of overlap syndromes.

It may seem surprising to have found $M$ fermentans in synovial specimens from patients with different inflammatory rheumatic diseases which are not usually considered to have an infectious aetiology, but not in specimens from patients with reactive arthritis, a disease which is clearly related to infectious disorders. However, neither $M$ fermentans nor $M$ penetrans have been implicated in non-gonococcal urethritis and they are not considered to cause diarrhoea. ${ }^{24}$ Three of our patients had diarrhoea initially, and Yersinia was isolated from a stool culture of one of them. The four other patients had sexually acquired reactive arthritis and Ureaplasma urealyticum was isolated from the genital tract of two of them. In this regard, it is interesting that the only mycoplasmas which have been suspected to cause reactive arthritis are $U$ urealyticum ${ }^{25}$ and possibly $M$ genitalium. ${ }^{23}$ So, the triggering infection was clearly related to organisms different from those sought by us in the present study.

We believe that this study should be expanded to seek $M$ fermentans and other mycoplasmas in patients from other geographical areas, that emphasis should be placed on early stage disease and that the organisms should be sought not only in synovial fluid samples but in synovial biopsy specimens too, in view of our particular success in detecting them in the latter. Although the organisms in the joints may not often be viable, as is the case with $C$ trachomatis in reactive arthritis, ${ }^{21}$ attempts should be made again to isolate mycoplasmas by culture; if viable, recovery might be achieved best through the combined use of cell culture, PCR and acellular medium, as has proved successful in isolating $M$ genitalium from patients with urethritis, ${ }^{26}$ although the hazard of this approach with $M$ fermentans which is a common contaminant of cell cultures is clear. Finally, $M$ fermentans antibody profiles in groups of patients with the aforementioned arthritides should be evaluated as a further means of defining the role of this mycoplasma.

1 Behar SM, Porcelli SA. Mechanisms of autoimmune disease induction. The role of the immune response to microbial pathogens. Arthritis Rheum 1995;38:458-76. 
2 Silman AJ. Is rheumatoid arthritis an infectious disease? BMF 1991;303:200-1.

3 Rook GAW, Lydyard PM, Stanford JL. A reappraisal of the evidence that rheumatoid arthritis and several other evidence that rheumatoid arthritis and several other
idiopathic diseases are slow bacterial infections. Ann Rheum idiopathic diseases are

4 Cole BC, Washburn LR, Taylor-Robinson D. Mycoplasmainduced arthritis. In: Razin S, Barile MF, eds. The mycoplasmas. Vol 4. Mycoplasma pathogenicity. New York: Academic Press, 1985:108-50.

5 Williams MH. Pathogenic mycoplasma in rheumatoid arthritis? In: pathogenic mycoplasma-A Ciba foundation symposium. Amsterdam: Associated Scientific Publishers, 1972:251-62.

6 Williams MH, Brostoff J, Roitt IM. Possible role of Mycoplasma fermentans in pathogenesis of rheumatoid Mycoplasma fermentans in pat

7 Mårdh PA, Nilsson FJ, Bjell A. Mycoplasmas and bacteria in synovial fluid from patients with rheumatoid arthritis. in synovial fluid from patients with
Ann Rheum Dis 1973;32:319-25.

8 Schaeverbeke T, Renaudin H, Clerc MC, de Barbeyrac B, Bébéar C, Bannwarth B, et al. Mycoplasmas and arthritis: a systematic culture study of synovial fluids. Arthritis Rheum 1994;37:S315.

9 Barile MF, Yoshida H, Roth H. Rheumatoid arthritis: new findings on the failure to isolate or detect mycoplasmas by multiple cultivation or serologic procedures and review of the literature. Rev Infect Dis 1991;13:571-82.

10 Taylor-Robinson D. Genital mycoplasmas. Curr Opin Infect Dis 1995;8:16-21.

11 Katseni VL, Gilroy CB, Ryait BK, Ariyoshi K, Bieniasz PD, Weber JN, et al. Mycoplasma fermentans in individuals seropositive and seronegative for HIV-1. Lancet 1993;341:271-3.

12 Lo SC, Hayes MM, Tully JG, Wang RYH, Kotani H, Pierce PF, et al. Mycoplasma penetrans sp. nov., from the urogenital tract of patients with AIDS. Int 7 Syst Bacteriol 1992;42:357-64.

13 Arnett FC, Edworth SM, Bloch DA, McShane DJ, Fries JF, Cooper NS, et al. The American Rheumatism Association 1987 revised criteria for the classification of rheumatoid 1987 revised criteria for the classification
arthritis. Arthritis Rheum 1988;31:315-24.

14 Dougados $M$, van der Linden S, Juhlin R, Huitfeldt B, Amor B, Calin A, et al. The European Spondyloarthropathy Study Group preliminary criteria for the classification of spondyloarthropathy. Arthritis Rheum 1991;34:1218-27.
15 Wilson K. In: Ausubel FM, ed. Current protocols in molecular biology. New York: John Wiley and Sons, 1987:1987-8.

16 Grau O, Kovacic R, Griffais R, Launay V, Montagnier L. Development of PCR-based assay for the detection of two human mollicute species, Mycoplasma penetrans and $M$ human mollicute species, Mycoplasma penetrans and M

17 Hu WS, Wang, RY-H, Liou R-S, Shih W-K, Lo S-C. Identification of an insertion sequence-like genetic element in the newly recognized human pathogen Mycoplasma incognitus. Gene 1990;93:67-72.

18 Rivera JA, Yanez A, Cedillo L. Experimental arthritis produced by Mycoplasma fermentans in rabbits. 95th 으 American Society of Microbiology General Meeting. $\because$ Washington, 1995.

19 Leng $Z$, Kenny GE, Roberts $M$. Evaluation of the detection limits of PCR identification of Mycoplasma pneumoniae in 7 clinical samples. Mol Cell Probe 1994;8:125-30.

20 Washburn LR, Cole BC, Gelman M, Ward JR. Chronic arthritis of rabbit induced by Mycoplasmas. I. Clinical, microbiologic and histologic features. Arthritis Rheum $\mathbb{D}$ 1980;23:825-36.

21 Keat A, Thomas B, Dixey J, Osborn M, Sonnex C, TaylorRobinson D. Chlamydia trachomatis and reactive arthritis: the missing link. Lancet 1987;i:72-4.

22 Pando JA, Yarboro C, Ellaban A, Saaibi D, Kanik K, Villalba L, et al. Prevalence of Chlamydia trachomatis by PCR $\vec{\omega}$ in the joint of patients with early rheumatoid arthritis. Arthritis Rheum 1995;38:S287.

23 Taylor-Robinson D, Gilroy CB, Horowitz S, Horowitz J. 응 Mycoplasma genitalium in the joints of two patients with $\overrightarrow{0}$

24 Deguchi T, Gilroy CB, Taylor-Robinson D. Failure to detect $\vec{\circ}$ Mycoplasma fermentans, Mycoplasma penetrans, or $\infty$ Mycoplasma pirum in the urethra of patients with acute $N$ nongonococcal urethritis. Eur $\mathcal{f}$ Clin Microbiol Infect Dis $千$ 1996;15:169-71.

25 Horowitz S, Horowitz J, Taylor-Robinson D, Sukenik S, Apte RN, Bar-David J, et al. Ureaplasma urealyticum in $\vec{O}$ Reiter's syndrome. $₹$ Rheumatol 1994;21:877-82.

26 Jensen JS, Hansen HT, Lind K. Isolation of Mycoplasma $\frac{\rho}{\vec{Q}}$ genitalium strains from the male urethra. $\mathcal{f}$ Clin Microbiol 1996;34:286-91. 